\title{
Prevalence of Adverse Drug Events in Severely Obese Adults and Associated Factors: Clinical Trial Baseline Results
}

\author{
Ana Carolina Figueiredo Modesto $1, * \mathbb{C}$, Erika Aparecida Silveira $1,2, * \mathbb{0}$, \\ Annelisa Silva e Alves de Carvalho Santos 1,3 ${ }^{\mathbb{D}}$, Ana Paula dos Santos Rodrigues 1,4, \\ Dione Marçal Lima ${ }^{5}$, Mércia Pandolfo Provin ${ }^{5}$ and Rita Goreti Amaral ${ }^{5}$ \\ 1 Post-Graduate Program in Health Sciences, School of Medicine, Federal University of Goiás, \\ Goiás 74605-050, Brazil; annelisa.nut@gmail.com (A.S.e.A.d.C.S.); anaprs@gmail.com (A.P.d.S.R.) \\ 2 School of Medicine, Federal University of Goiás, Goiás 74605-050, Brazil \\ 3 United Faculty of Campinas, Goiás 74535-280, Brazil \\ 4 Goiás Health Department, Goiás 74860-270, Brazil \\ 5 School of Pharmacy, Federal University of Goiás, Goiás 74605-170, Brazil; \\ dione.farmacia@gmail.com (D.M.L.); merciap@gmail.com (M.P.P.); ritagoreti26@gmail.com (R.G.A.) \\ * Correspondence: farmcarolina@gmail.com (A.C.F.M.); erikasil@terra.com.br (E.A.S.)
}

Received: 12 August 2020; Accepted: 15 September 2020; Published: 23 September 2020

\begin{abstract}
Drugs are the most widely used therapeutic tool for treatment of diseases. However, misuse can lead to an adverse drug event (ADE) in susceptible individuals such as those that are severely obese. This study aimed to describe the frequency of ADEs, the associations of ADEs with anatomical therapeutic chemical classes and their respective frequency, estimate the prevalence of ADEs, and analyse factors associated with ADE in adults with severe obesity. Cross-sectional analysis of baseline data from a randomized clinical trial in the central-western region of Brazil. A total of 150 individuals aged 18-65 years with a Body Mass Index of $35 \mathrm{~kg} / \mathrm{m}^{2}$ were included. The outcome variable was the presence of ADE and the explanatory variables were socio-demographic factors, lifestyle, health, and medication use. ADEs were associated with use of drugs for the digestive tract and metabolism $(p<0.001)$ and the cardiovascular system $(p<0.001)$. The prevalence of ADEs was 32.67\% $(n=49)$ and associated with the age range 40 to 49 years $(p=0.033)$, diabetes $(p=0.004)$, multimorbidities $\geq 4$ $(p=0.009)$, self-medication (0.031), and presence of potential drug interactions (0.017). The prevalence of ADEs was high and was associated with drugs commonly used in treatment of obesity-related morbidities and self-medication. The introduction of a pharmacist to multi-professional teams can improve medication safety for severely obese patients.
\end{abstract}

Keywords: severe obesity; adverse drug events; drug utilization reviews; randomized controlled trial; pharmacoepidemiology; diabetes mellitus; multimorbidities; self-medication

\section{Introduction}

The drug is the most widely used therapeutic tool for the diagnosis, prophylaxis, and treatment of diseases [1]. Undeniably, drug therapy has evolved through history and has improved people's quality of life [2]. However, misuse of medications can lead to adverse drug events (ADE) [3], which are defined as instances of harm to the patient that result from the use of drugs in doses commonly used for the prophylaxis and treatment of disease as well as from errors in their use [3].

Some risk factors of ADEs are known, such as age, multimorbidities, and polypharmacy [1]. Polypharmacy [4] is a major challenge faced by health professionals who care for patients with chronic diseases [5]. The presence of multimorbidities is associated with increased medication use, and 
individuals with multimorbidities are almost 15 times more likely to develop an ADE compared with healthy individuals [6].

Another potential risk factor for ADEs is obesity, a condition of abnormal or excessive fat accumulation in adipose tissue [7] that can lead to the development of multimorbidities that require the chronic use of drugs, such as diabetes, hypertension, cardiovascular disease, dyslipidaemia, osteoarticular problems, and a number of cancers $[8,9]$. Moreover, obesity can also reduce the drug efficacy [10], which may lead to potential drug-related problems. Severe obesity, characterised by a body mass index $(\mathrm{BMI}) \geq 35 \mathrm{~kg} / \mathrm{m}^{2}$, is the fastest growing BMI category in the world and is associated with increased morbidity and mortality rates [9].

Studies on drug use in obese individuals are scarce, and existing studies focus on potential therapeutic targets of treatment [11-13]. Regarding the safety of medication use in obese people, the available literature is limited to describing adverse events associated with obesity treatment [14] without considering the use of concomitant therapy. Studies on ADEs in obese individuals, and in particular, severely obese individuals, are rare. Research on the use of medicines is particularly important to fill the gap regarding medication safety in real life contexts [15].

Given that $35 \%$ of the US population is obese, it can be extrapolated that, of the 16,651 drug-related deaths that occur annually in the US, approximately 5800 obese individuals die from ADEs every year [16]. Although similar data have not been found in other countries, the alarming global rate of growth of severe obesity in recent years [9] and the risk of ADEs for obese individuals make the development of research on this subject vital. Here, we hypothesize that severely obese individuals are more susceptible to experiment an ADE because they have multimorbidities and use many drugs. Considering the gap observed in the literature, the objectives of this study were (a) to describe the frequency of ADEs by organs and systems; (b) to describe the associations with ADEs of Anatomical Therapeutic Chemical (ATC) classes and their respective frequency; (c) estimate the prevalence of ADEs; and (d) analyse the possible factors associated with an ADE in adults with severe obesity.

\section{Materials and Methods}

\subsection{Setting and Study Design}

This study was a cross-sectional analysis of baseline data from the DieTBra Trial (Effect of Nutritional Intervention and Olive Oil in Severe Obesity: Randomised Controlled Trial), which aimed to evaluate the effects of nutritional treatment on inflammation, weight loss, and biochemical markers in severely obese individuals with records in ClinicalTrials.gov study NCT02463435. Patients were referred from the Brazilian Unified Health System (UHS) of primary healthcare to the Nutrition and Severe Obesity Outpatient Clinic in a large university hospital in the Central-West Region of Brazil. We excluded from the study individuals that had already undergone bariatric surgery; were under actual nutritional treatment for weight loss or had been in the previous 2 years; were using antiobesity drugs; had HIV/AIDS, heart/kidney/hepatic insufficiency, chronic obstructive pulmonary disease, or cancer; and pregnant women. Further methodological details can be found in DieTBra Trial articles with baseline data published elsewhere [17,18].

In the trial protocol, all drug use variables and analyses were pre-specified in baseline data and approved by the Ethical Committee. Data regarding drug use were collected by a trained pharmacist according to a standard operational procedure from June 2015 to February 2016. All the participants gave their written consent to participate in this study, conforming to the Helsinki declaration. This study was approved by the Local Research Ethics Committee with registration number 1.545.504.

\subsection{Subjects}

The subjects in the study included individuals aged 18 to 65 years with BMI $\geq 35 \mathrm{~kg} / \mathrm{m}^{2}$ [7], who were referred from primary care to an outpatient clinic specialising in the care of severely obese patients. Individuals residing outside the metropolitan area who had already undergone bariatric surgery that 
reduced more than $8 \%$ of their weight in the last three months, who had received treatment, or who were currently being treated for obesity at the same outpatient clinic as well as pregnant women, infants, and those with special needs were excluded. During the follow-up, we had two withdrawals: one patient was hospitalized due to pneumonia and another claimed lack of time to attend the clinic visits.

\subsection{Variables}

The outcome variable was the presence of ADEs [3], as assessed by the question: "Do you notice any different symptoms with the use of this medication?" This question was asked for each medication used by the patient and categorised as "yes" when the patient had at least one symptom suggestive of ADEs and "no" when there was no symptom. Symptoms were then categorised according to the classification of organs and systems and the Medical Dictionary for Regulatory Activities [19].

The analytical variables were divided into four categories: sociodemographic, lifestyle, health condition, and drug use.

\subsubsection{Sociodemographic}

Sociodemographic factors included sex, age, years of study, skin colour, relationship status, and economic class determined by Brazil's standard economic classification criteria [20].

\subsubsection{Lifestyle}

The consumption of alcoholic beverages was estimated by asking patients about the amount of alcohol they had consumed the previous week [21]. Smoking responses were categorised as "non-smoker", "ex-smoker", or "smoker" [22].

\subsubsection{Health}

BMI was calculated by dividing body weight in kilograms by the square of height in meters. Patients with BMI $\geq 35 \mathrm{~kg} / \mathrm{m}^{2}$ and $\geq 40 \mathrm{~kg} / \mathrm{m}^{2}$ were classified as having grade II and grade III obesity, respectively [7]. Arterial hypertension was classified by blood pressure levels of $\geq 140 / 90 \mathrm{~mm} / \mathrm{Hg}$ [23] and/or the use of antihypertensive drugs. Diabetes mellitus (DM) was classified by fasting plasma glucose values $\geq 126 \mathrm{mg} / \mathrm{dL}$ [24] and/or use of antidiabetic drugs. Hypercholesterolemia was classified by the presence of one or more of the following conditions: isolated hypercholesterolemia, isolated hypertriglyceridemia, mixed hyperlipidaemia or low-density lipoprotein [25], or use of anti-lipemic drugs. Multimorbidities [7] consisted of the number of diseases reported by the patient in the interview.

\subsubsection{Drug Use}

The use of drugs that cause weight gain $[8,10,26,27]$ and polypharmacy, which is the practice of using five or more drugs [28], were categorised as "yes" or "no". Self-medication [29] was assessed by asking, "Do you have a prescription?" for each drug used by the patient, and answers were classified as "yes" or "no" according to the patient's habitual use of non-prescription drugs. The drugs used by the patient were classified according to the ATC classification system [30]. Non-ATC and phytotherapeutic drugs were categorised as non-classifiable, as they are not included in the ATC classification. Potential drug interactions (PDI) were estimated by searching the Micromedex ${ }^{\circledR}$ [31] database for all drugs used by the patient. Subsequently, the PDI was reclassified when at least one PDI was identified and considered absent when no PDI was identified.

\subsection{Data Collection}

All data collection was performed by a trained multiprofessional team according to the standard operating procedures of the clinical trial. Sociodemographic, drug therapy, and anthropometric data were collected by a psychologist and a physiotherapist, a pharmacist, and a nutritionist, respectively. 


\subsection{Statistical Analyses}

The association of variables was tested by Pearson's chi-square test, Fischer's exact test, or linear trend chi-square test. Multiple Poisson regression was performed by hierarchical model, and variables with $p$-value $<0.20$ in the bivariate analysis were included in the multiple model. The first level included sociodemographic and lifestyle variables, the second level included health, and the third level included the use of medication. Variables that did not retain an association were removed from the final model. The measure of effect was presented as the prevalence ratio, with a 95\% confidence interval (CI). All analyses were performed using Stata software, version 14, with a significance level of $5 \%$.

\section{Results}

Among the 150 subjects included in the study, the prevalence of ADEs was $32.67 \%(n=49)(95 \%$ CI 41-58). As shown in Table 1, the symptoms most commonly reported as ADEs were related to gastrointestinal tract disorders, one-third of which were stomach aches $(n=10,33.33 \%)$, followed by nausea and vomiting $(n=9,30.00 \%)$. Central nervous system-related adverse effects ranked second, the most frequent being drowsiness $(n=15,75.00 \%)$ and headaches $(n=2,10.00 \%)$.

Table 1. Frequency of adverse drug events in severely obese adults, by organ and system classification.

\begin{tabular}{cc}
\hline Adverse Drug Events & $\boldsymbol{n} \mathbf{( \% )}$ \\
\hline Gastrointestinal disorders & $30(61.22)$ \\
Nervous system disorders & $20(40.82)$ \\
Skin and subcutaneous tissue disorders & $3(6.12)$ \\
Cardiac disorders & $2(4.08)$ \\
General disorders and administration site conditions & $2(4.08)$ \\
Renal and urinary disorders & $2(4.08)$ \\
Respiratory, thoracic, and mediastinal disorders & $2(4.08)$ \\
Blood and lymphatic system disorders & $1(2.04)$ \\
Metabolism and nutrition disorders & $1(2.04)$ \\
Musculoskeletal, connective tissue, and bone disorders & $1(2.04)$ \\
Reproductive system and breast disorders & $1(2.04)$ \\
\hline
\end{tabular}

The therapeutic classes that were associated with ADEs were the alimentary tract and metabolism $(p<0.001)$ and the cardiovascular system $(p<0.001)$ (Table 2$)$.

Table 2. Frequency and association of drug groups by ATC classification involved in adverse drug events in adults with severe obesity.

\begin{tabular}{|c|c|c|c|c|}
\hline & ATC Classification & Total n (\%) & ADE Presence & $p$ Value \\
\hline A & Alimentary Tract and metabolism & $57(38.00 \%)$ & $30(52.63 \%)$ & $0.000 *$ \\
\hline $\mathrm{B}$ & Blood and forming blood organs & $11(7.33 \%)$ & $6(54.55 \%)$ & $0.108 *$ \\
\hline $\mathrm{D}$ & Dermatological & 0 & 0 & 0 \\
\hline G & Genito urinary system and sex hormones & $12(8.00 \%)$ & $3(25.00 \%)$ & $0.406^{* *}$ \\
\hline $\mathrm{H}$ & Systemic hormonal preparations, excluding sex hormones and insulins & $10(6.67 \%)$ & $5(50.00 \%)$ & 0.226 * \\
\hline $\mathrm{M}$ & Musculo-skeletal system & $97(64.67 \%)$ & $37(38.14 \%)$ & $0.053 *$ \\
\hline $\mathrm{N}$ & Nervous system & $86(57.33 \%)$ & $29(33.72 \%)$ & $0.750 *$ \\
\hline $\mathrm{P}$ & Antiparasitic products, insecticides and repellents & $1(0.67 \%)$ & $0(0 \%)$ & - \\
\hline $\mathrm{R}$ & Respiratory system & $17(11.33 \%)$ & $5(29.41 \%)$ & $0.761 *$ \\
\hline $\mathrm{S}$ & Sensory organs & $1(0.67 \%)$ & $0(0 \%)$ & - \\
\hline
\end{tabular}

The variables associated with ADE in the bivariate analysis were age group of 40 to 49 years $(p=0.030)$, arterial hypertension $(p=0.001)$, diabetes mellitus $(p=0.001)$, number of multimorbidities 
$(p=0.001)$, use of drugs that cause weight gain $(p=0.011)$, polypharmacy $(p<0.001)$, and potential drug interactions $(p<0.001)$ (Table 3$)$.

Table 3. Frequency of adverse drug events and their association with sociodemographic variables, lifestyle, health profile, and drug use in severely obese adults $(n=150)$.

\begin{tabular}{|c|c|c|c|c|}
\hline Variables & Total n (\%) & Presence of ADE & PR (CI 95\%) & $p$-Value \\
\hline \multicolumn{5}{|l|}{ Sex } \\
\hline Male & 22 (14.67) & $6(27.27)$ & 1.00 & $0.559 *$ \\
\hline Female & $128(85.33)$ & $43(33.59)$ & $1.23(0.59-2.54)$ & \\
\hline \multicolumn{5}{|l|}{ Age } \\
\hline $18-39$ & $76(50.67)$ & $18(23.68)$ & 1.00 & $0.030^{* *}$ \\
\hline $40-49$ & $53(35.33)$ & $22(41.51)$ & 1.75 (1.04-2.93) & \\
\hline$\geq 50$ & $21(14.00)$ & $9(42.86)$ & $1.80(0.95-3.43)$ & \\
\hline \multicolumn{5}{|l|}{ Skin Color } \\
\hline White & $46(30.67)$ & $16(34.78)$ & $1.15(0.68-1.93)$ & 0.734 * \\
\hline Brown & $83(55.33)$ & $25(30.12)$ & 1.00 & \\
\hline Black & $21(14.00)$ & $8(38.10)$ & $1.26(0.66-2.39)$ & \\
\hline \multicolumn{5}{|l|}{ Economic Class } \\
\hline Class A/B & $34(22.67)$ & $12(35.29)$ & $1.20(0.68-2.09)$ & $0.484^{*}$ \\
\hline Class C & $92(61.33)$ & $27(29.35)$ & 1.00 & \\
\hline Class D/E & $24(16.00)$ & $10(41.67)$ & $1.41(0.80-2.51)$ & \\
\hline \multicolumn{5}{|c|}{ Lives with Partner } \\
\hline No & $55(36.67)$ & $19(34.55)$ & $1.09(0.68-1.75)$ & $0.709 *$ \\
\hline Yes & $95(63.33)$ & $30(31.58)$ & 1.00 & \\
\hline \multicolumn{5}{|l|}{ Smoking } \\
\hline No & $101(67.33)$ & $32(31.68)$ & 1.00 & $0.712 *$ \\
\hline Yes & $49(32.67)$ & $17(34.69)$ & 1.09 (0.67-1.77) & \\
\hline \multicolumn{5}{|c|}{ Alcohol Intake $(\mathrm{n}=84)$} \\
\hline No & $13(15.48)$ & $3(23.08)$ & 1.00 & $0.301^{* * *}$ \\
\hline Yes & $71(84.52)$ & $27(38.03)$ & $1.64(0.58-4.67)$ & \\
\hline \multicolumn{5}{|l|}{ Body Mass Index } \\
\hline $35-39$ & $27(18.00)$ & $11(40.74)$ & $1.31(0.77-2.23)$ & $0.323 *$ \\
\hline$\geq 40$ & $123(82.00)$ & $38(30.89)$ & 1.00 & \\
\hline \multicolumn{5}{|c|}{ Arterial Hypertension } \\
\hline No & $65(43.33)$ & 12 (18.46) & 1.00 & $0.001 *$ \\
\hline Yes & $85(56.67)$ & $37(43.53 \%)$ & $2.35(1.33-4.15)$ & \\
\hline \multicolumn{5}{|l|}{ Diabetes } \\
\hline No & $90(60.00)$ & $20(22.22)$ & 1.00 & $0.001 *$ \\
\hline Yes & $60(40.00)$ & $29(48.33)$ & $2.17(1.36-3.47)$ & \\
\hline \multicolumn{5}{|c|}{ Hypercholesterolemia } \\
\hline No & $94(62.67)$ & $29(30.85 \%)$ & 1.00 & $0.539 *$ \\
\hline Yes & $56(37.33)$ & $20(35.71 \%)$ & $1.15(0.72-1.84)$ & \\
\hline \multicolumn{5}{|l|}{ Comorbidities } \\
\hline$\leq 3$ & 89 (59.33) & $20(22.47)$ & 1.00 & $0.001 *$ \\
\hline$\geq 4$ & $61(40.67)$ & $29(47.54)$ & $2.11(1.32-3.38)$ & \\
\hline \multicolumn{5}{|l|}{ Drugs that Cause } \\
\hline \multicolumn{5}{|l|}{ Weight Gain } \\
\hline No & $106(70.67 \%)$ & $28(26.42 \%)$ & 1.00 & $0.011 *$ \\
\hline Yes & $44(29.33 \%)$ & $21(47.73 \%)$ & $1.80(1.15-2.81)$ & \\
\hline \multicolumn{5}{|l|}{ Self-Medication } \\
\hline 0 & $23(15.33 \%)$ & $6(26.09 \%)$ & 1.00 & $0.178 *$ \\
\hline $1-2$ & $89(59.33 \%)$ & $26(29.21 \%)$ & $1.11(0.52-2.40)$ & \\
\hline$\geq 3$ & $38(25.33 \%)$ & $17(44.74 \%)$ & $1.71(0.78-3.72)$ & \\
\hline \multicolumn{5}{|l|}{ Polypharmacy } \\
\hline No & $101(67.33 \%)$ & $19(18.81 \%)$ & 1.00 & $<0.001$ * \\
\hline Yes & $49(32.67 \%)$ & $30(61.22 \%)$ & $3.25(2.04-5.17)$ & \\
\hline \multicolumn{5}{|l|}{ Potential Drug } \\
\hline \multicolumn{5}{|l|}{ Interactions } \\
\hline No & $75(50.00)$ & $12(16.00)$ & 1.00 & $<0.001^{*}$ \\
\hline Yes & $75(50.00)$ & 37 (49.33) & $3.08(1.60-5.91)$ & \\
\hline
\end{tabular}


The variables that remained associated with ADE after multiple analysis were: age group 40 to 49 years $(p=0.033)$, diabetes mellitus $(p=0.004)$, number of multimorbidities $\geq 4(p=0.009)$, self-medication with three or more drugs $(p=0.031)$, and potential drug interactions $(p=0.017)$ (Table 4).

Table 4. Multiple regression of possible factors associated with adverse drug events in severely obese adults $(n=150)$.

\begin{tabular}{lccc}
\hline \multicolumn{1}{c}{ Variables } & Adjusted Prevalence Ratio & CI 95\% Adjusted & $p$ Value * \\
\hline Age & & & \\
$18-39$ & 1.00 & $1.04-2.93$ & 0.033 \\
$40-49$ & 1.75 & $0.95-3.43$ & 0.069 \\
$\geq 50$ & 1.81 & & \\
\hline Diabetes & & & \\
No & 1.00 & $1.26-3.29$ & 0.004 \\
Yes & 2.03 & & \\
\hline Comorbidities & & & \\
$\leq 3$ & 1.00 & & \\
$\geq 4$ & 1.91 & & \\
\hline Self-medication & & $0.17-3.11$ & 0.290 \\
0 & 1.00 & $1.07-4.35$ & 0.031 \\
$1-2$ & 1.45 & & \\
$\geq 3$ & 2.15 & $1.15-4.26$ & 0.017 \\
\hline Potential drug interactions & & &
\end{tabular}

\section{Discussion}

Judging by the literature review, this study pioneers a risk factor analysis of ADEs in severely obese individuals. The high prevalence of ADEs in these individuals was associated with age, diabetes mellitus, number of multimorbidities, self-medication, and potential drug interactions. These findings are relevant to the clinical area of obesity treatment and to multi-professional teams motivated to avoid occurrences of ADEs. Especially considering that the prevalence of severe obesity has significantly increased in the world population, accompanied by rising health care costs, worsening quality of life for individuals, and increased mortality [9,32], these results highlight the importance of investigating patterns of drug use and of ADEs in severely obese patients.

This study found a high prevalence of ADE, but no studies were found that evaluate this outcome in individuals with $\mathrm{BMI} \geq 35 \mathrm{~kg} / \mathrm{m}^{2}$ or in obese people in general. A similarly high prevalence of ADEs also exists among people with chronic diseases such as HIV (52.7\%) [33] and among the elderly in the United States (42.9\%) [34].

Regarding ADEs classified by organs and systems, results from our study were similar to those found in other studies. About one-third reported gastrointestinal tract (GIT) symptoms, and $10 \%$ reported central nervous system (CNS)-related symptoms [33,35]. The high prevalence of GIT symptoms can be explained by obesity itself, which is a risk factor for hepatic steatosis [36,37], abdominal pain, nausea, vomiting, and diarrhoea [37]. In addition, hepatic steatosis may be associated with changes in drug metabolism, which contribute to the manifestation of GIT-related symptoms [38]. Although CNS-related symptoms have not yet been physiologically elucidated, obesity has been associated with sleep disorders [39], which could explain the sleepiness presented by the patients in our study.

Regarding ATC classes and their association with ADEs, the results of our study are in line with others on adults with chronic diseases, showing a higher prevalence of ADE among those who 
use drugs for the digestive tract and metabolism and for the cardiovascular system [35,40]. These associations can be interpreted two ways. In the treatment of diabetes, oral antidiabetics and insulin are not only common but also high-alert medications precisely because they present a risk of harm to the patient, such as hypoglycaemia [41]. The association between ADEs and this class of drugs in several groups of individuals is well described in the literature [42,43]. Additionally, metformin use in severely obese patients increases the chance of developing hepatic steatosis by almost one-and-a-half times [36], which may partly explain the GIT-related symptoms in our study. Although considered safe, metformin use, especially in obese individuals, should be monitored. Liver function tests and imaging tests should be ordered at the beginning of treatment to assess progression of liver injury.

An age-adjusted analysis showed increased ADE among 40- to 49-year-olds compared with 18- to 39-year-olds. This association, however, did not occur among individuals older than 50, remaining within the limit of significance. As there are no previous studies with which to compare our results, we drew a parallel to studies on the elderly with chronic diseases, a systematic review of which showed a higher prevalence of ADEs in these individuals [44].

The association of ADEs with DM in our study has also been observed in India [45]. This association can be explained by two distinct mechanisms. DM is a condition that can affect the pharmacokinetics and pharmacodynamics [46] of medications and contribute to the occurrence of ADEs. DM treatment is also a risk factor for ADE, as antidiabetic drug use is the third leading cause of hospitalization in the United States [47]. One ADE in diabetes patients is hypoglycaemia, which can lead to severe neurological damage and hospitalization [48]. It is noteworthy that DM is prevalent in severely obese individuals [48], and MI for these patients can be even more severe than for non-obese people if they are not effectively monitored by a multi-professional team. Monitoring these patients may minimise the occurrence of severe ADEs and provide much safer therapy [47]. The adoption of a validated tool to evaluate patients at risk for the development of severe hypoglycaemia is suggested [4].

We observed a significant association of ADEs with multimorbidities and PDI in severely obese individuals, clinical variables that are interconnected. Although no previous studies about ADEs among the obese or severely obese have been identified, a systematic review has shown that individuals with multimorbidities are twice as likely to experience an ADE [49]. These findings may be explained by the fact that these patients require complex health care and therapeutic regimens with many medications, making them more susceptible to ADEs [50]. Likewise, no studies evaluating PDI that resulted in ADEs in severely obese patients were found. Considering the predictability of some PDI [51], greater attention is needed from health professionals in the management of individuals at risk of ADEs due to PDI. The same attention is needed for those with multimorbidities.

The association between ADEs and self-medication in severely obese patients is consistent with a systematic review of the elderly, among whom an increased risk of ADEs in those who self-medicate was observed [52]. In Germany, it was reported that $4 \%$ of hospitalizations of the elderly were associated with ADEs caused by self-medication [53]. In both studies, most patients complained of GIT-related symptoms [52,53], similar to the results of our study. These results may be partially attributable to the fact that self-medication is a common behaviour in patients with multimorbidities [52].

Socio-demographic variables were not associated with ADEs in obese patients; therefore, the results of our study are in line with those of other studies conducted in Brazil [35,54]. No other studies were found that analysed the impact of BMI as a risk factor for ADEs in both obese and chronically ill patients. Clinical variables are more associated with ADEs compared with sociodemographic variables [35].

The strength of our study is that it is a baseline analysis of a randomised clinical trial that followed rigorous methodological criteria and met all the precepts of good clinical research practice. The number of severely obese individuals is relevant, considering the prevalence of this class of obesity reaching $0.64 \%$ in men and $1.6 \%$ in the world [32], with the highest health risks in this group.

A possible limitation of this research is recall bias because of a reliance on the patient as a source of information about ADEs. However, other studies have already highlighted the value of patients 
self-reporting medication use, as their reports provide important details regarding ADEs, such as the circumstances of their drug use [55].

As obesity is a risk factor for the development of other chronic diseases, more studies assessing the causality of ADEs are needed to elucidate important aspects that differentiate a new symptom from a new ADE. Drug use in individuals with severe obesity should be carefully analysed, since it is a population with multimorbidities, usually cared for by a team of health professionals. This fact may contribute to the chronic use of multiple medications, which in turn may contribute to the manifestation of ADEs. Pharmacoepidemiological studies involving the pharmacotherapy of other morbidities in obese patients are scarce in the literature, so the results of our study may help in the management of drug use safety in severely obese individuals.

\section{Conclusions}

The prevalence of ADEs was high, affecting more than one-third of patients and was associated with drugs commonly used in treatment of obesity related morbidities and self-medication. Considering the relevance of medication safety to the world health agenda [1], the introduction of a pharmacist to the multi-professional teams leading structured medication reviews can improve medication safety for severely obese patients.

Author Contributions: Conceptualization, E.A.S. and R.G.A.; methodology, E.A.S., A.P.d.S.R., M.P.P., D.M.L., and R.G.A.; validation, A.P.d.S.R. and A.S.e.A.d.C.S.; formal analysis, E.A.S., A.C.F.M., A.P.d.S.R., M.P.P., and A.S.e.A.d.C.S.; investigation, E.A.S. and A.P.d.S.R.; data curation, E.A.S., A.P.d.S.R.; writing-original draft preparation, A.C.F.M., A.S.e.A.d.C.S., and A.P.d.S.R.; writing—review and editing, A.C.F.M., M.P.P., R.G.A., and D.M.L.; visualization, A.C.F.M.; supervision, E.A.S. and R.G.A.; project administration, E.A.S.; and funding acquisition, E.A.S. All authors have read and agreed to the published version of the manuscript.

Funding: This research was funded by Research Support Foundation of the State of Goiás (FAPEG), grant number 201310267000003.

Acknowledgments: We would like to thank all study participants and undergraduate volunteers who participated in our study and all the Clinical Research Unit/UFG. We would also like to thank the Nutrition in Severe Obesity Outpatient Clinic (ANOG), the Clinical Hospital/UFG, and the Goiânia Municipal Health Secretariat. We thank all DieTBra Trial researchers for their effort to produce this high-quality research.

Conflicts of Interest: The authors declare no conflict of interest.

\section{References}

1. World Health Organization. Medication without Harm-Global Patient Safety Challenge on Medication Safety; World Health Organization: Geneva, Switzerland, 2017.

2. Ferner, R.E.; Butt, T.F. Adverse drug reactions. Medicine 2008, 36, 364-368. [CrossRef]

3. World Health Organization. The Conceptual Framework for the International Classification for Patient Safety Version 1.1 Final Technical Report; World Health Organization: Geneva, Switzerland, 2009.

4. Molokhia, M.; Majeed, A. Current and future perspectives on the management of polypharmacy. BMC Fam. Pract. 2017, 18, 70. [CrossRef]

5. Doos, L.; Roberts, E.O.; Corp, N.; Kadam, U.T. Multi-drug therapy in chronic condition multimorbidity: A systematic review. Fam. Pract. 2014, 31, 654-663. [CrossRef]

6. Calderón-Larrañaga, A.; Poblador-Plou, B.; González-Rubio, F.; Gimeno-Feliu, L.A.; Abad-Díez, J.M.; Prados-Torres, A. Multimorbidity, polypharmacy, referrals, and adverse drug events: Are we doing things well? Br. J. Gen. Pract. 2012, 62, 821-826. [CrossRef] [PubMed]

7. World Health Organization. Obesity: Preventing and Managing the Global Epidemic; World Health Organization: Geneva, Switzerland, 2000.

8. Apovian, C.M. Obesity: Definition, comorbidities, causes, and burden. Am. J. Manag. Care 2016, 22, 176-185.

9. The Global Burden of Disease 2015 Obesity Collaborators. Health Effects of Overweight and Obesity in 195 Countries over 25 Years. N. Engl. J. Med. 2017, 377, 13-27. [CrossRef] [PubMed]

10. Hansel, K.; Bianchi, L.; Lanza, F.; Bini, V.; Stingeni, L. Adalimumab Dose Tapering in Psoriasis: Predictive Factors for Maintenance of Complete Clearance. Acta Derm. Venereol. 2017, 97, 346-350. [CrossRef] 
11. Apovian, C.M.; Aronne, L.J.; Bessesen, D.H.; McDonnell, M.E.; Murad, M.H.; Pagotto, U.; Ryan, D.H.; Still, C.D. Pharmacological Management of Obesity: An Endocrine Society Clinical Practice Guideline. J. Clin. Endocrinol. Metab. 2015, 100, 342-362. [CrossRef]

12. Narayanaswami, V.; Dwoskin, L.P. Obesity: Current and potential pharmacotherapeutics and targets. Pharmacol. Ther. 2016, 170, 116-147. [CrossRef]

13. Seoane, L.; Barja-Fenández, S.; Leis, R.; Casanueva, F.F.; Barja-Fernandez, S. Drug development strategies for the treatment of obesity: How to ensure efficacy, safety, and sustainable weight loss. Drug Des. Dev. Ther. 2014, 8, 2391-2400. [CrossRef]

14. Khera, R.; Murad, M.H.; Chandar, A.K.; Dulai, P.S.; Wang, Z.; Prokop, L.J.; Loomba, R.; Camilleri, M.; Singh, S. Association of pharmacological treatments for obesity with weight loss and adverse events: A systematic review and meta-analysis. JAMA 2016, 315, 2424. [CrossRef] [PubMed]

15. Liu, Q.; Ramamoorthy, A.; Huang, S.-M. Real-World Data and Clinical Pharmacology: A Regulatory Science Perspective. Clin. Pharmacol. Ther. 2019, 106, 67-71. [CrossRef] [PubMed]

16. Zuckerman, M.; A Greller, H.; Babu, K.M. A Review of the Toxicologic Implications of Obesity. J. Med. Toxicol. 2015, 11, 342-354. [CrossRef] [PubMed]

17. Silveira, E.A.; de Souza Rosa, L.P.; de Souza Cardoso, C.K.; Noll, M. Type 2 Diabetes Mellitus in Class II and III Obesity: Prevalence, Associated Factors, and Correlation between Glycemic Parameters and Body Mass Index. Int. J. Environ. Res. Public Health 2020, 17, 3930. [CrossRef] [PubMed]

18. Santos, A.S.; Rodrigues, A.P.S.; Rosa, L.P.; Sarrafzadegan, N.; Silveira, E.A. Cardiometabolic risk factors and Framingham Risk Score in severely obese patients: Baseline data from DieTBra trial. Nutr. Metab. Cardiovasc. Dis. 2020, 30, 474-482. [CrossRef]

19. Brown, E.G.; Wood, S.; Brown, E.G.; Wood, L. The Medical Dictionary for Regulatory Activities (MedDRA). Drug Saf. 1999, 20, 109-117. [CrossRef]

20. Abep. Critério Padrão de Classificação Econômica Brasil. pp. 1-3. Available online: http://www.academia. edu/download/48356646/CCE.pdf (accessed on 11 August 2020).

21. Bloomfield, K.; Allamani, A.; Beck, F.; Bergmark, K.H.; Csemy, L.; Eisenbach-Stangl, I.; Elekes, Z.; Gmel, G.; Ker-Correa, F.; Knibbe, R.; et al. Gender, Culture and Alcohol Problems: A Multi-National Study; Institute for Medical Informatics: Berlin, Germany, 2005.

22. Organizacíón Panamericana de la Salud. Guias Para el Control y Monitoreo de la Epidemia Tabaquica; Organizacíón Panamericana de la Salud: Caracas, Venezuela, 1995.

23. National Cholesterol Education Program Expert Panel on Detection E and T of HBC in A. Third Report of the National Cholesterol Education Program (NCEP) Expert Panel on Detection, Evaluation, and Treatment of High Blood Cholesterol in Adults (Adult Treatment Panel III) final report. Circulation 2002, 106, 3143-3421. [CrossRef]

24. American Diabetes Association. Standard of medical care in diabetes-2017. Diabetes Care 2017, 40 (Suppl. 1), s4-s128. [CrossRef]

25. Drozda, J.; Messer, J.V.; Spertus, J.; Abramowitz, B.; Alexander, K.; Beam, C.T.; Bonow, R.O.; Burkiewicz, J.S.; Crouch, M.; Goff, D.C.; et al. ACCF/AHA/AMA-PCPI 2011 Performance Measures for Adults With Coronary Artery Disease and Hypertension: A Report of the American College of Cardiology Foundation/American Heart Association Task Force on Performance Measures and the American Medical Association—Physician Consortium for Performance Improvement. Circulation 2011, 124, 248-270.

26. Keith, S.W.; Redden, D.T.; Katzmarzyk, P.T.; Boggiano, M.M.; Hanlon, E.C.; Benca, R.M.; Ruden, D.; Pietrobelli, A.; Barger, J.L.; Fontaine, K.R.; et al. Putative contributors to the secular increase in obesity: Exploring the roads less traveled. Int. J. Obes. 2006, 30, 1585-1594. [CrossRef]

27. Domecq, J.P.; Prutsky, G.; Leppin, A.; Sonbol, M.B.; Altayar, O.; Undavalli, C.; Wang, Z.; Elraiyah, T.; Brito, J.P.; Mauck, K.F.; et al. Drugs Commonly Associated with Weight Change: A Systematic Review and Meta-analysis. J. Clin. Endocrinol. Metab. 2015, 100, 363-370. [CrossRef] [PubMed]

28. Guharoy, R. Polypharmacy: America's other drug problem. Am. J. Health-Syst. Pharm. 2017, 74, 1305-1306. [CrossRef]

29. World Health Organization. The Role of the Pharmacist in Self-Care and Self-Medication Content; World Health Organization: Geneva, Switzerland, 1998.

30. World Health Organization. Guidelines for ATC Classification and DDD Assignment 2015. Vol. 1, WHO Collaborating Centre for Drug Statistics Methodology; World Health Organization: Geneva, Switzerland, 2015. 
31. Truven Health Analytics. Micromedex; Truven Health Analytics: Greenwood Village, CO, USA, 2017.

32. NCD Risk Factor Collaboration. Trends in adult body-mass index in 200 countries from 1975 to 2014 : A pooled analysis of 1698 population-based measurement studies with 19.2 million participants. Lancet 2016, 387, 1377-1396. [CrossRef]

33. Tetteh, R.A.; Nartey, E.T.; Lartey, M.; Mantel-Teeuwisse, A.K.; Leufkens, H.G.M.; Yankey, B.A.; Dodoo, A.N.O. Association Between the Occurrence of Adverse Drug Events and Modification of First-Line Highly Active Antiretroviral Therapy in Ghanaian HIV Patients. Drug Saf. 2016, 39, 1139-1149. [CrossRef]

34. Mazzanti, G.; Vitalone, A.; Da Cas, R.; Menniti-Ippolito, F. Suspected adverse reactions associated with herbal products used for weight loss: Spontaneous reports from the Italian Phytovigilance System. Eur. J. Clin. Pharmacol. 2019, 75, 1599-1615. [CrossRef] [PubMed]

35. De Sousa, L.A.O.; Fonteles, M.M.D.F.; Monteiro, M.P.; Mengue, S.S.; Bertoldi, A.D.; Pizzol, T.D.S.D.; Tavares, N.U.L.; Oliveira, M.A.; Luiza, V.L.; Ramos, L.R.; et al. Prevalência e características dos eventos adversos a medicamentos no Brasil. Cad. Saúde Pública 2018, 34. [CrossRef] [PubMed]

36. Moctezuma-Velazquez, C.; Márquez-Guillén, E.; Torre, A. Obesity in the Liver Transplant Setting. Nutrients 2019, 11, 2552. [CrossRef] [PubMed]

37. Camilleri, M.; Malhi, H.; Acosta, A. Gastrointestinal Complications of Obesity. Gastroenterology 2017, 152, 1656-1670. [CrossRef]

38. Li, X.; Wang, L.; Li, D.; Niu, J.; Gao, P. Dyslipidemia is a Risk Factor for the Incidence and Severity of Drug-Induced Liver Injury (DILI): A Retrospective Population-Based Study in China. Med. Sci. Monit. 2019, 25, 3344-3353. [CrossRef]

39. Sasaki, N.; Fujiwara, S.; Yamashita, H.; Ozono, R.; Monzen, Y.; Teramen, K.; Kihara, Y. Association between obesity and self-reported sleep duration variability, sleep timing, and age in the Japanese population. Obes. Res. Clin. Pract. 2018, 12, 187-194. [CrossRef]

40. Huber, C.A.; Szucs, T.D.; Rapold, R.; Reich, O. Identifying patients with chronic conditions using pharmacy data in Switzerland: An updated mapping approach to the classification of medications. BMC Public Health 2013, 13, 1030. [CrossRef]

41. Singh, A.A.; Adams, A.; Dudley, B.; Davison, E.; Jones, L.; Wales, L. Making surgical wards safer for patients with diabetes: Reducing hypoglycaemia and insulin errors. BMJ Open Qual. 2018, 7, e000312. [CrossRef]

42. Zhou, Q.; Zhao, R.-Y.; He, X.-W.; Shan, Y.-M.; Zhu, L.-L. A stewardship intervention program for safe medication management and use of antidiabetic drugs. Clin. Interv. Aging 2015, 10, 1201-1212. [CrossRef] [PubMed]

43. Ratanawongsa, N.; Chan, L.L.S.; Fouts, M.M.; Murphy, E.J. The Challenges of Electronic Health Records and Diabetes Electronic Prescribing: Implications for Safety Net Care for Diverse Populations. J. Diabetes Res. 2017, 2017, 1-7. [CrossRef] [PubMed]

44. Kanagaratnam, L.; Dramé, M.; Trenque, T.; Oubaya, N.; Nazeyrollas, P.; Novella, J.; Jolly, D.; Mahmoudi, R. Adverse drug reactions in elderly patients with cognitive disorders: A systematic review. Maturitas 2016, 85, 56-63. [CrossRef] [PubMed]

45. Singh, A.; Dwivedi, S. Study of adverse drug reactions in patients with diabetes attending a tertiary care hospital in New Delhi, India. Indian J. Med. Res. 2017, 145, 247-249. [PubMed]

46. Dostalek, M.; Akhlaghi, F.; Puzanovova, M. Effect of diabetes mellitus on pharmacokinetic and pharmacodynamic properties of drugs. Clin. Pharmacokinet. 2012, 51, 481-499. [CrossRef]

47. Shehab, N.; Lovegrove, M.C.; Geller, A.I.; Rose, K.O.; Weidle, N.J.; Budnitz, D.S. US emergency department visits for outpatient adverse drug events, 2013-2014. JAMA 2016, 316, 2115-2125. [CrossRef]

48. Geller, A.I.; Shehab, N.; Lovegrove, M.C.; Scott, R.; Weidenbach, K.N.; Ryan, G.J.; Budnitz, D.S. National estimates of insulin-related hypoglycaemia and errors leading to emergency department visits and hospitalizations. JAMA 2014, 174, 678-686.

49. Karter, A.J.; Warton, E.M.; Lipska, K.J.; Ralston, J.D.; Moffet, H.H.; Jackson, G.G.; Huang, E.S.; Miller, D.R. Development and validation of a tool to identify patients with type 2 diabetes at high risk of hypoglicemia-related emergency department or hospital use. JAMA Intern. Med. 2019, 177, 1461-1470. [CrossRef]

50. Panagioti, M.; Stokes, J.; Esmail, A.; Coventry, P.A.; Cheraghi-Sohi, S.; Alam, R.; Bower, P. Multimorbidity and Patient Safety Incidents in Primary Care: A Systematic Review and Meta-Analysis. PLoS ONE 2015, 10, e0135947. [CrossRef] 
51. Banda, J.M.; Callahan, A.; Winnenburg, R.; Strasberg, H.R.; Cami, A.; Reis, B.Y.; Vilar, S.; Hripcsak, G.; Dumontier, M.; Shah, N.H. Feasibility of Prioritizing Drug-Drug-Event Associations Found in Electronic Health Records. Drug Saf. 2015, 39, 45-57. [CrossRef] [PubMed]

52. Locquet, M.; Honvo, G.; Rabenda, V.; Van Hees, T.; Petermans, J.; Reginster, J.-Y.; Bruyère, O. Adverse Health Events Related to Self-Medication Practices Among Elderly: A Systematic Review. Drugs Aging 2017, 34, 359-365. [CrossRef] [PubMed]

53. Schmiedl, S.; Rottenkolber, M.; Hasford, J.; Rottenkolber, D.; Farker, K.; Drewelow, B.; Hippius, M.; Saljé, K.; Thurmann, P.A. Self-Medication with Over-the-Counter and Prescribed Drugs Causing Adverse-Drug-Reaction-Related Hospital Admissions: Results of a Prospective, Long-Term Multi-Centre Study. Drug Saf. 2014, 37, 225-235. [CrossRef] [PubMed]

54. Giordani, F.; Rozenfeld, S.; Martins, M. Adverse drug events identified by triggers at a teaching hospital in Brazil. BMC Pharmacol. Toxicol. 2014, 15, 71. [CrossRef]

55. Watson, S.; Chandler, R.E.; Taavola, H.; Härmark, L.; Grundmark, B.; Zekarias, A.; Star, K.; Van Hunsel, F. Safety Concerns Reported by Patients Identified in a Collaborative Signal Detection Workshop using VigiBase: Results and Reflections from Lareb and Uppsala Monitoring Centre. Drug Saf. 2018, 41, 203-212. [CrossRef]

(C) 2020 by the authors. Licensee MDPI, Basel, Switzerland. This article is an open access article distributed under the terms and conditions of the Creative Commons Attribution (CC BY) license (http://creativecommons.org/licenses/by/4.0/). 